\title{
PROCESSO DE MEDIAÇÃO NO CONTEXTO ESCOLAR: UMA PRÁTICA NECESSÁRIA NA RELAÇÃO CRIANÇA E TELEVISÃO.
}

Jéssika Naiara da Silva; Leonardo de Angelo Orlandi, José Milton de Lima, Márcia Regina Canhoto de Lima

Faculdade de Ciências e Tecnologias - UNESP - Campus de Presidente Prudente. Agência financiadora: PIBIC-CNPq. Email: jessika 4@hotmail.com

\section{RESUMO}

Têm-se como objetivo da presente pesquisa examinar a relação existente entre infância e cultura midiática e levantar os posicionamentos que os educadores necessitam assumir como mediadores no processo educativo, visando à valorização das brincadeiras no ambiente da Educação Infantil. A metodologia selecionada para alcançar tais objetivo é a qualitativa, configurando-se como pesquisa do tipo etnográfica, no qual a presença na realidade investigada é fundamental para a obtenção dos resultados esperados. Os resultados demonstraram que as crianças trazem para o ambiente escolar os conteúdos provenientes das mídias televisivas e diante disso, como em todas as situações e processos educacional que envolvem as crianças, os adultos têm um papel fundamental de mediador, esclarecendo e dialogando a respeito dos conteúdos e situações observados durante a programação televisivas pelas crianças e que comparecem nas brincadeiras infantis frequentemente.

Palavras-chaves: mediação; televisão; contexto educacional; criança; dialogo.

\section{INTRODUÇÃO E OBJETIVO}

Inicialmente, antes de apresentar os objetivos de tal pesquisa, apresentaremos os pressupostos e concepções que nortearam os estudos bibliográficos e as visões durante a observação no ambiente da Educação Infantil.

Diante disso, partimos do pressuposto de que a Educação Infantil deve conhecer, respeitar e possibilitar experiências que favoreçam as atividades principais das crianças, ou seja, aquelas que geram mais desenvolvimento para as crianças de três entre cinco anos, que é a idade dos sujeitos da pesquisa, sendo as brincadeiras.

No entanto, tal conhecimento é necessário ir adiante e compreender que a brincadeira deve ser reconhecida como resultado da cultura, estando sujeita a modificações, segundo o contexto sócio-cultural. As transformações nas diversas esferas: econômica, social, cultural e política, alteram a brincadeira nas suas formas e conteúdos, e tornam-se cada vez mais indispensável a interpretação, a influência e a atuação dos educadores no desenvolvimento de hábitos lúdicos e na ampliação do acervo das culturas da infância. 
Brougère (1998, p. 6) afirma que a cultura lúdica (conjunto de procedimentos que tornam possível o jogo, referências que permitem identificar tal atividade como jogo) está inserida em uma cultura geral, consequentemente se apodera de elementos como a mídia para compor-se. "A televisão, assim como o brinquedo, transmite hoje conteúdos e às vezes esquemas que contribuem para a modificação da cultura lúdica que vem se tornando internacional". Desde muito cedo, as crianças têm contato com os meios de comunicação e, nessa interação, elas se apropriam dos conteúdos e os expressam por meio das brincadeiras.

Corsaro (2009) explica que as crianças não só imitam, mas apreendem criativamente os conteúdos vindos do mundo adulto para atender seus próprios interesses infantis. Complementando essa visão Borba (2006) afirma que, a criança, ao estar em contato com os produtos culturais, é ativa na reinterpretação por meio de cruzamento de culturas e de significações construídas nas relações com seus pares.

Investigações e estudos constantes são necessários para compreender, entre outras questões, quais os tipos de atividades que compõem a cultura lúdica, quais são os seus temas e conteúdos, quem são os agentes de divulgação e mediação, de que maneira a sociedade e o sistema educacional têm tratado e valorizado essa atividade. Esta pesquisa, portanto, apoiada em estudos de natureza antropológica e sociológica, examina a relação existente entre infância e cultura midiática e levanta os posicionamentos que os educadores necessitam assumir como mediadores no processo educativo com vistas à valorização da atividade lúdica na infância.

A respeito da presença da mídia no contexto escolar, Buckingham (2007, p. 293) afirma: “é extraordinário que o currículo das escolas continue a negligenciar as formas de cultura e comunicação que cominam tão inteiramente o século XX e continuarão a dominar o século XXI".

É impossível negar o contato da criança com as mídias, por isso ressalta-se que o educador deve estar atento as ações que a criança apresenta - em especial nas brincadeiras - para que assim possa intervir de forma a ajudá-las a refletir sobre os conteúdos produzidos na instituição. “As crianças apenas poderão tornar-se 'cidadãs ativas', capazes de fazer escolhas sensatas em questões políticas, se forem consideradas capazes de fazê-lo" (BUCKINGHAM, 2007, p.245).

\section{METODOLOGIA}

$\mathrm{Na}$ busca de elucidar os objetivos propostos a investigação adotou a metodologia qualitativa, pois não tinha como objetivo enumerar e/ou medir dados coletados, assim focaliza um 
determinado espaço social e cultural, visando compreender seus valores e práticas (VIÉGAS, 2007, p. 104).

Dessa forma, elegeu a Etnografia como suporte metodológico. Para Lüdke e André (1986, p. 6) esse procedimento "tem um sentido muito próprio: é a descrição de um sistema de significados culturais de um determinado grupo", do qual o ensino deve ser pensado dentro de um contexto cultural amplo. Desse modo, essa abordagem metodológica implicou em: estar no local, participar, observar, conversar e registrar as experiências por escrito.

Em relação aos procedimentos metodológicos, a pesquisa utiliza técnicas de observação, entrevistas, questionários, levantamento bibliográfico e diário de campo. Desse modo, a metodologia e os procedimentos adotados foram aplicados no trabalho de campo realizado pela pesquisadora. Tal processo contemplou nove turmas da Educação Infantil no Município de Álvares Machado/SP, entre elas crianças de três, quatro e cinco anos de idade pertencentes ao Infantil I e Infantil II, totalizando aproximadamente 180 crianças e nove educadoras.

Assim, o conhecimento produzido foi elaborado por meio do aprofundamento teórico e do trabalho de campo, trazendo relatos, conhecimentos e informações a respeito da cultura lúdica e da mediação no contexto escolar, e por fim possibilitou apresentar posicionamentos referentes ao tema.

Número do protocolo de cadastramento no Comitê de Ética e Pesquisa: 802009

\section{RESULTADOS}

As observações realizadas na instituição pesquisada demonstraram que as crianças, tanto os meninos como as meninas, apresentam manifestações com conteúdos oriundos dos programas televisivos, especialmente os dos desenhos animados, nas culturas lúdicas infantis.

Em diversos momentos durante as brincadeiras no pátio, nas intervenções, na brinquedoteca e até mesmo em sala de aula, as crianças questionam se iram brincar das brincadeiras com temas da programação televisiva. Segue abaixo algumas das mais repetidas frases que são feitas para a pesquisadora e para as professoras, nelas podemos perceber uma pergunta, porém, sempre com um tom de pedido:

"Vamos brincar de Bem-10?"

"Vamos brincar de Homem Aranha?"

"Vamos brincar com Barbie hoje?"

(fala das crianças dos Infantis I e II) 
Além das crianças sempre estarem pedindo que as brincadeiras apresentam conteúdos ou temas com origem nos desenhos animados, elas também fazem comparações entre a vida real e as ações, falas e objetos dos personagens dos desenhos animados. Como será demonstrado logo abaixo, quando o Marcelo ${ }^{1}$ do Inf. II dá uma sugestão no meio da brincadeira, declarando-se da seguinte forma:

"Ah já sei, vamos fazer igual o Pica-Pau."

Ou então, como na frase abaixo, quanto Bruna do Inf. Il compara a fala de Alex com a do Cebolinha:

"Professora, ele fala errado igual o Cebolinha da Mônica."

Ao terminar de falar ela dá muita risada, e assim, sua declaração faz com que toda a turma caia na risada também, inclusive Alex que havia falado errado. Isso demonstra que as crianças haviam relacionado Alex com o personagem Cebolinha, não necessitando de uma explicação de quem era, ou o que fazia tal personagem. Nesse sentido, percebe-se que as crianças dessa turma já tiveram um contado com tal personagem e com sua fala cheia de erros.

Percebeu-se também, que as crianças sempre gostam de falar sobre sua vida pessoal, contar algo que aconteceu com sua família, contar onde que passaram o final de semana, onde passearam, entre outras coisas. É durante essas conversas que elas falam sobre os presentes que ganharam ou irão ganhar, principalmente gostam de contar sobre aqueles presentes, roupas, calçados e até alimento dos personagens televisivos. Veja abaixo uma conversa que aconteceu durante a "roda de conversa" realizada no pátio da instituição, no qual, a professora estava explicando como seria a brincadeira do "macaco pula pula".

João Paulo que estava sentado ao meu lado direito virou e falou:

- Meu aniversário vai ter um bolo do Ben-10.

Otávio que estava sentado ao meu lado esquerdo houve a conversa e completa:

- E o meu do Batman.

Matheus que também estava sentado perto indaga:

- Pro. o meu vai se dos Carros do Maguin.

\footnotetext{
${ }^{1}$ Todos os nomes citados são nomes fictícios.
} 
Outro dia, também na roda de conversa Juliana me chamou e começou a falar:

- Você sabia que eu moro com a minha mãe?E eu tenho um quarto da Barbie, uma coberta das Princesas e desenho das bonecas.

- E você gosta? (pesquisadora)

- Gosto. E você sabia que tem até Tv da Barbie.

$\mathrm{Na}$ instituição pesquisa foi comum perceber que as crianças gostam de falar das coisas que têm, que ganharam ou que ainda irão ganhar, elas demonstram satisfação e contentamento ao fazer essas declarações. Nota-se que ao falarem sobre o que elas têm dos personagens televisivos é uma boa forma de instigar ou começar um assunto/conversa.

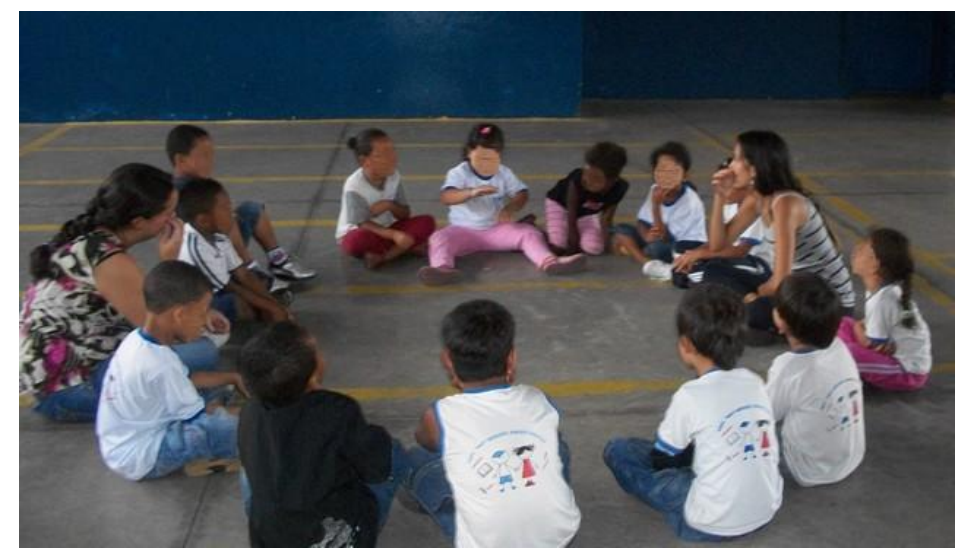

Roda de conversa com uma das turmas

\section{DISCUSSÃO}

Diante da realidade observada e a partir do aprofundamento teórico apresentado, nos questionamos: Como deve atuar o professor no momento em que surge situações como as citadas acima, considerando-se a brincadeira como meio de aquisição e compreensão do mundo? Segundo a Teoria Histórico-Cultural (THC), o docente se torna o mediador, ou seja, aquele que tem conhecimentos sobre a criança e a infância e, a partir disso, propõe situações intencionalmente desafiadoras auxiliando o desenvolvimento da criança. Vygotsky (1988, apud MARTINS, 1993, p. 6) explica que há uma zona de desenvolvimento real $^{2}$, uma zona de desenvolvimento potencial ${ }^{3} \mathrm{e}$ uma zona de desenvolvimento próximo.

Nesse caso, o professor atua na zona de desenvolvimento próximo "que se expressa pelo que a criança não é ainda capaz de fazer de forma independente, mas pode fazer com ajuda do

\footnotetext{
${ }^{2}$ As funções já estão maduras, a zona é caracterizada pela capacidade da criança de resolver problemas de forma independente.

${ }^{3}$ As funções ainda estão em fase de maturação, a zona é caracterizada pela capacidade de a criança resolver problemas com o auxílio. 
outro" (MELLO, 2007, p. 98). Aquilo que está latente ou em estado de formação pode ser desenvolvido com a intervenção docente, já que na zona de desenvolvimento próximo está alocado o estágio em que há aprendizagem. Portanto, a atuação com pares, adultos (dentre eles, os professores) e objetos são fundamentais para o desenvolvimento multilateral da criança.

A criança, em idade pré-escolar, está em processo de formação de conhecimentos, habilidades e qualidades psíquicas mais gerais e fundamentais para a vida em sociedade; dito de outro modo, aquisição qualitativa e quantitativa da linguagem, ação sobre os objetos, percepção, pensamento, memória, imaginação, concentração, orientação espaço-temporal, domínio da vontade, maior socialização, desenvolvimento da motricidade, etc.

Nessa perspectiva, a Teoria Histórico-Cultural (THC) aponta que a brincadeira (faz-de-conta e jogos de papéis) é entendida como atividade principal no desenvolvimento da criança na idade pré escolar. Por atividade principal, compreende-se ser aquela que gera maior influência no desenvolvimento da criança em determinada idade. Segundo Leontiev (1987, apud FACCI, 2006, p.13) "o desenvolvimento dessa atividade condiciona as mudanças mais importantes nos processos psíquicos da criança e nas particularidades psicológicas da sua personalidade". Mello implementa inferindo que,

[...] as mudanças mais significativas de sua personalidade, o conhecimento do mundo físico e social, e a organização e reorganização dos processos de pensamento, de compreensão do mundo e de expressão estão ligados à atividade principal em cada idade - representada pela comunicação emocional no primeiro ano de vida, pela atividade de tateio com objetos na 1 a infância e pelo jogo de papéis na idade pré-escolar (2007, p. 93).

Desse modo, é de suma importância que o educador conheça as atividades principais e as necessidades individuais de cada criança, e busque estimular e proporcionar o desenvolvimento integral nas múltiplas linguagens, principalmente através das brincadeiras.

Nesse sentido, o educador deve estar presente nos momentos de brincadeiras das crianças, sempre interagindo, conversando e observando a concepção que as crianças têm em relação às brincadeiras de conteúdos das mídias e assim intervir problematizando as questões que suscitam durante as atividades.

Nas brincadeiras infantis o objeto brinquedo assume um espaço privilegiado. Porém, essa importância já é conhecida pelas mídias em geral, pois são diversos os produtos, brinquedos, objetos, roupas e calçados desenvolvidos para o público infantil, tais produtos estão presentes a 
todo o momento nas atividades lúdicas, na cultura de pares e nas conversas das crianças, sendo possível observar o contato direto com as mídias, porém e a televisão que se sobressai.

Sobre a influência da televisão na atividade lúdica, Brougère (2004) analisa a produção dos brinquedos e destaca a sua importância como elemento na difusão da cultura da infância, nos esclarece também, que há muito tempo os brinquedos derivados dos filmes são explorados como mercadoria para o público infantil, todavia, a televisão fortaleceu esse fenômeno.

Nessa perspectiva, em relação às brincadeiras e produtos infantis influenciados pelas mídias, Girardello (2010, p.4) aponta que "os heróis, heroínas e aventuras da TV são usados como matéria-prima da vida de fantasia das crianças. As narrativas da televisão funcionam como uma espécie de para a brincadeira imaginativa das crianças". Perguntamo-nos, então: por que não aproveitar essas narrativas na Educação Infantil e problematizar e enriquecer os conteúdos que alimentam a imaginação das crianças durante as atividades lúdicas?

Para tal posicionamento, é preciso consciência por parte do educador para que esse tipo de linguagem seja incorporado nas práticas cotidianas, ou seja, o papel do professor não é o de impedir as vivências lúdicas das crianças, com argumentos e conteúdos assimilados em outros espaços sociais ou pela televisão, mas, a partir da constatação, o de ressignificar as experiências assimiladas pelas crianças e auxiliar para a incorporação de outros referenciais na esfera lúdica.

\section{CONCLUSÕES}

Assim, a partir das explanações acima, concluímos que as crianças apresentam e representam no ambiente da Educação Infantil os conteúdos, roupas, acessórios e falas provenientes do contato com a mídia televisiva.

Dessa forma, como em todas as situações e processos educacional que envolvem as crianças, os adultos têm um papel fundamental de mediação, esclarecendo e dialogando a respeito dos conteúdos e situações observados durante a programação e que comparecem nas brincadeiras frequentemente. Nessa direção, Lima (2008, p. 144) ressalta que "no contexto educacional, o professor exerce o papel de mediador entre a criança e a cultura lúdica, e a sua intervenção é essencial para que os educandos ampliem e diversifiquem seus conhecimentos sobre jogos e brincadeiras".

Por fim, finalizamos afirmando que para alcançar uma Educação Infantil de qualidade, que privilegie as culturas lúdicas como elemento essencial no processo humanizador das crianças, devemos nos apropriar da seguinte conclusão: se o educador oferece e possibilita momentos de 
brincadeiras infantis às crianças, ao chegarem em casa elas terão um repertório lúdico para reproduzir e interagir com os irmãos, primos, vizinhos, amigos, responsáveis ou até mesmo sozinhos, e, assim, reduzir, o tempo que passariam sentadas assistindo televisão, o que terá conseqüências positivas no desenvolvimento da linguagem, da autonomia, da percepção, pensamento, memória, imaginação, organização, concentração, como também no domínio da vontade, maior socialização, desenvolvimento da motricidade, coordenação motora e orientação espaço-temporal.

\section{REFERÊNCIAS}

BORBA, Ângela M. O brincar como um modo de ser e estar no mundo. In: BRASIL, MEC/SEB Ensino fundamental de nove anos: orientações para a inclusão da criança de seis anos de idade. organização Jeanete Beauchamp, Sandra Denise Rangel, Aricélia Ribeiro do Nascimento - Brasília: Ministério da Educação, Secretaria de Educação Básica, 2006

BROUGÈRE, G. A criança e a cultura lúdica. Revista da Faculdade de Educação, São Paulo, vol.24, n.2., jul/dez, 1998.

BROUGÈRE, G.. Brinquedos e Companhia. São Paulo: Cortez, 2004.335p

BUCKINGHAM, D. Crescer na era das mídias eletrônicas. São Paulo: Loyola, 2007, 301 p.

CORSARO, W. A. Reprodução Interpretativa e Cultura de Pares. In: MÜLLER, F.; CARVALHO, A. M. A. (orgs.). Teoria e prática na pesquisa com crianças: Diálogos com William Corsaro. São Paulo: Cortez, 2009.

GIRARDELLO, G. A imaginação e as historias da TV. Disponível em < Ateliê da Aurora: http://www.aurora.ufsc.be/artigos/artigos_imaginação.htm> acesso em junho de 2010.

LEONTIEV, A. N. Os princípios psicológicos da brincadeira pré-escolar. In: VYGOTSKY, L. S. Linguagem, desenvolvimento e aprendizagem. 4. ed. São Paulo: Ícone: EDUSP, 1988.

LIMA, J. M. O Jogo como Recurso Pedagógico no Contexto Educacional. São Paulo: Cultura Acadêmica: Universidade Estadual Paulista , Pró-Reitoria de Graduação, 2008, 157p.

LUDKE, Menga; ANDRÉ, Marli E. D. A. Pesquisa em Educação: abordagens qualitativas. São Paulo: EPU, 1986.

MELLO, S. A. Infância e humanização: algumas considerações na perspectiva histórico-cultural. Perspectiva, Florianópolis, v. 25, n. 1, 83-104, jan./jun. 2007. Disponível em: <www.perspectiva.ufsc.br/perspectiva_2007_01/6-Suely.pdf> Acesso em: 05 mai 2011.

VIÉGAS, Lygia de Souza. Reflexões sobre a pesquisa etnográfica em Psicologia e Educação. Diálogos Possíveis, Bahia, n. 09, jan/jun, 2009. 
VYGOTSKY, L. S., LURIA, A. R., LEONTIEV, A. N. Linguagem, desenvolvimento e aprendizagem. 4. ed. São Paulo: Ícone: EDUSP, 1988. 